\title{
Экономика Чернавского
}

\author{
А. В. Щербаков \\ НПО «Курс», \\ Россия, 141707, Московская обл., г. Долгопрудный, Лихачевский проезд, д. 26 \\ E-mail: andrey-iron1@yandex.ru
}

Получено 07.04.2017, после доработки - 22.05.2017. Принято к публикаиии 31.05.2017.

\begin{abstract}
В настоящей статье изложен научный подход Дмитрия Сергеевича Чернавского к вопросам моделирования экономических процессов. Излагается история работы Дмитрия Сергеевича на экономическом направлении, представлены ее основные этапы и достижения. Одним из важнейших достижений в области экономического анализа стало предсказание группой ученых, возглавляемых Д. С. Чернавским, основных кризисов, произошедших в нашей стране за последние 20 лет, а именно дефолта 1998 года, кризиса промышленного производства второй половины 2000-х, кризиса 2008 года и последовавшей за ним рецессии. В качестве примера динамического анализа мировых макроэкономических процессов приведена модель функционирования доллара в качестве мировой валюты. На данном конкретном примере показана возможность сеньёража за счет эмиссии доллара и рассчитано «окно возможностей», которое позволяет эмитировать доллары в качестве мировой валюты без ущерба для собственной экономики.

Как пример динамического анализа экономики отдельного государства рассматривается модель развития закрытого общества (без внешних экономических связей) в однопродуктовом приближении. Модель основана на принципах рыночной экономики, то есть динамика цены определяется балансом спроса и предложения. Показано, что в общем случае состояние рыночного равновесия не единственно. Возможно несколько стационарных состояний, отличающихся уровнем производства и потребления. Рассмотрен эффект адресной денежной эмиссии в низкопродуктивном состоянии. Показано, что в зависимости от ее размера и адреса она может привести к переходу в высокопродуктивное состояние и просто вызвать инфляцию без перехода. Обсуждается связь этих результатов с кейнсианским и монетаристским подходами.
\end{abstract}

Ключевые слова: экономика, кризисы, динамический анализ, доллар, сеньёраж, математическая модель, эмиссия, инфляция, цифровая экономика 
UDC: 330.4

\title{
Economy of Chernavskii
}

\author{
A. V. Scherbakov \\ "Kurs" Ltd., \\ 26 Lihachevsky avenue, Dolgoprudny, Moscow region, 141700, Russia \\ E-mail: andrey-iron1@yandex.ru
}

Received 07.04.2017, after completion - 22.05.2017. Accepted for publication 31.05.2017.

The present article sets out the scientific approach of Dmitry Sergeevich Chernavskii to the modelling of economic processes. It recounts the history of works of Dmitry Sergeyevich on the economic front, its milestones and achievements. One of the most important advances in the economic analysis was the prediction by a team of scientists headed by D. S. Chernavskii, the major crises that have occurred in our country over the last 20 years, namely, the default of 1998, the crisis of industrial production in the second half of the 2000s, the 2008 crisis and the ensuing recession. As an example, the dynamic analysis of the global macroeconomic processes shows the model of functioning of the dollar as the world currency. On this particular example shows the possibility of seigniorage due to the issue of the dollar and the calculated "window of opportunity" that allows you to issue dollars as the global currency, without prejudice to its own economy.

A model for the development of a closed society (without external economic relations) in the one-product approach is considered as an example of dynamic analysis of the economy of a separate state. The model is based on the principles of market economy, i.e. the dynamics of prices is determined by the balance of supply and demand. It is shown that in the general case, the state of market equilibrium is not unique. Several steady states with different levels of production and consumption are possible. Effect of addressed emission of money in underproductive state is considered. It is shown that, depending on its size it can lead to the transition to a highly productive condition, and just cause inflation without transition. The relationship of these results with the "Keynesian" and "monetarist" approaches is discussed.

Keywords: the economy, crises, dynamic analysis, dollar, seigniorage, mathematical model, emission, inflation, the digital economy

Citation: Computer Research and Modeling, 2017, vol. 9, no. 3, pp. 397-417 (Russian). 


\section{Введение}

В 1990 году встретились ученый-физик и производственник-практик. Разговорились они о судьбе страны (тогда еще СССР), о путях ее экономического и политического развития.

Время тогда было смутное: перестройка, гласность, бурные дебаты в прессе. Кооперативы всех мастей всё более отвоевывали себе место под экономическим солнцем. Трудовые коллективы избирали себе по конкурсу директоров, брали в аренду цеха и целые предприятия.

Все это словоблудие и «экономическая пена» служили дымовой завесой для развала системы в интересах высших партийных элит прежних советских республик.

Призывы к гласности и демократии чаще всего предшествуют свержению существующей власти - к такому выводу пришли физик и производственник. И возникла идея: а не построить ли модель советского общества? Так родился знаменитый «двугорбый верблюд» (статья Чернавского Д. С. «У верблюда два горба, потому что жизнь - борьба», газета «Солидарность», № 9-10, 1991 г. [Чернавский, 1991]). Так родилась наша группа, объединенная идеей математического моделирования социальных и экономических процессов в обществе, под руководством Чернавского Д. С.

К сожалению, прогнозы о скором развале СССР сбылись, и в 1991 году мы оказались в совершенно другой стране.

В это время в среде экономистов шла оживленная дискуссия о необходимой либерализации цен. Наша группа выступала против либерализации, так как модель теперь уже российского общества показывала, что это приведет к росту цен за короткий период в десятки раз и обнищанию основной массы населения. Так и случилось в 1992 году в результате «гайдаровских реформ».

С 1992 года наша группа организационно оформилась в виде Лаборатории экономической синергетики. Мы активно сотрудничали с рядом коммерческих и производственных структур, делали аналитические обзоры для Министерства экономики, Министерства труда, Министерства обороны и других ведомств.

Своим главным достижением мы считали умение на основе построения математической модели прогнозировать развитие социально-экономических процессов, в том числе момент наступления «катастрофических» явлений как на уровне экономики страны в целом, так и на уровне отдельного предприятия.

Примерами такого прогнозирования может служить, например, крах фирмы «МММ», который мы просчитали за четыре месяца до обвала пирамиды Мавроди. Второй пример: осенью 1997 года в журнале «Полития», № 3 (5), в статье Чернавского Д. С. и Щербакова А. В. «Экономика России: стабилизация или застой» [Чернавский, Щербаков, 1997] с точностью до месяца был предсказан дефолт 1998 года.

С 1999 года в экономике России произошла стабилизация и стал заметен некоторый рост. Этот рост был воспринят рядом экономистов как начало «экономического чуда», был даже провозглашен тезис об удвоении ВВП в ближайшем будущем. Наш анализ показал, что только целенаправленное государственное регулирование может привести к действительному росту экономики. В противном же случае рост остановится и сменится стагнацией реального сектора экономики. Процесс этот займет 4-5 лет. Действительно, после 2003 года рост в реальном секторе ощутимо замедлился и во многих отраслях наметился спад.

Спад начала 2000-х вылился в очередной кризис в 2008 году. Сам кризис был предсказан нами за полгода (в апреле 2008 г.), а его причины и последствия были описаны в ряде аналитических работ 2009-2010 гг.

К 2014 году наша группа переросла за рамки лаборатории. Было принято решение организовать Центр социально-экономического прогнозирования им. Д. И. Менделеева. В настоящее время в рамках центра работает несколько десятков видных российских ученых-специалистов в области экономики, социологии, анализа сложных динамических систем.

К величайшему сожалению, летом 2016 года не стало одного из основателей и научного руководителя центра Дмитрия Сергеевича Чернавского. Настоящая статья посвящена его вкладу в изучение динамических процессов в экономике. 


\section{І. Окно возможностей, или модель сеньёража}

Одним из направлений динамического моделирования экономики является моделирование финансовой системы, в частности мировых финансов. Ниже изложена модель, описывающая поведение доллара в качестве мировой валюты. Впервые данная модель была опубликована в 2015 году [Чернавский, Щербаков, 2015].

Обсудим вербальный сценарий процесса.

В каждой отдельно взятой стране эмиссия валюты ограничена условием Фишера:

$$
\frac{v \bar{M}}{p_{\text {in }} \mathrm{BB}_{i n}}=1 .
$$

Здесь $\mathrm{BBП}_{\text {in }}-$ количество товара (агрегата товаров), производимого в год в естественных единицах («штуках»), $p_{\text {in }}$ - цена (в национальной валюте) единицы агрегированного товара на внутреннем рынке, $v$ - скорость производства $(v=1 / \tau$, где $\tau$ - время производственного цикла), $\bar{M}$ - оптимальное значение объема денежной массы. Отметим, что реальное значение может существенно отличаться от оптимального.

Смысл условия Фишера - обеспеченность национальной валюты произведенной продукцией внутри страны.

Динамика эмиссии валюты описывается логистическим уравнением:

$$
\frac{d M}{d t}=\frac{1}{\tau} A M(\bar{M}-M),
$$

где $M$ - текущее значение денежной массы, $\tau$ - время производственного цикла, $\bar{M}$ - оптимальное значение денежной массы из условия Фишера (1). Стационарное (равновесное) решение уравнения (2): $M=\bar{M}$. Параметр $A$ имеет размерность, обратную $M$ и по порядку величины: $A \cong 1 / \bar{M}$.

Учтем эффект участия национальной валюты в международной торговле в качестве мировой валюты (далее для конкретности будем считать, что $M$ - доллары США). Тогда количество этой валюты и ее равновесное значение должны быть больше: $\bar{M}_{t o t}=M+\Delta M$, где $\Delta M=b_{e x} p_{e x} \mathrm{BB} \prod_{e x} \tau_{e x}$ - дополнительная эмиссия национальной валюты с целью захватить внешний рынок. Здесь $p_{e x}$ - цена товара (в долларах) на вешнем рынке, она отличается от внутренней цены $p_{\text {in }}$ и может сильно меняться (в то время как $p_{\text {in }}$ поддерживается постоянной), ВВП $\prod_{e x}-$ объем внешней мировой торговли, $\tau_{e x}-$ характерное время внешнеторгового оборота. Коэффициент $b_{e x}$ отражает стремление захватить внешний финансовый рынок (т. е. экспансию доллара) и сам зависит от объема долларовой массы $M$, поскольку увеличение ее способствует этому стремлению. Далее мы примем: $b_{e x}=b M$.

Использование национальной валюты в мировой торговле выгодно стране-эмитенту, поскольку импортные товары оплачиваются в долларах, а последние эмитируются. Таким образом, страна-эмитент получает импортные товары фактически бесплатно, за счет дополнительной эмиссии. Эти средства уходят во внешний мир и не влияют на внутренние цены. Это явление известно давно (еще со Средних веков) и имеет название «сеньёраж».

Если та же валюта начинает использоваться внутри других стран (например, в качестве резервных фондов), то эти страны попадают в зависимость от страны-эмитента. Пока внешняя цена $p_{e x}$ стабильна, то такая ситуация не вызывает опасений. Однако она может оказаться неустойчивой. Тогда при росте эмиссии и росте цен $p_{e x}$ доллар обесценивается - его курс падает. Вместе с этим обесцениваются и резервные фонды других стран, аккумулированные в долларах, что равносильно экономической катастрофе мирового масштаба.

Понятие «курс» имеет смысл при обмене валют. Так называемый справедливый курс определяется из следующего условия: при обмене валют покупательная способность должна сохраняться. Тогда курс доллара по отношению, например, к евро, равен $Q(\$ / e)=p_{e} / p_{e x}$. Реальный 
обменный курс, как правило, далек от «справедливого», но общее положение остается в силе: курс доллара - величина, обратно пропорциональная цене $p_{e x}$.

Таким образом, основная задача модели - оценка устойчивости ситуации, когда доллар претендует на роль мировой валюты и описание процесса вблизи бифуркации.

\section{Математическая модель}

В качестве динамических переменных выберем денежную массу (долларов) $M$ и цену $p_{e x}$. Уравнение для $M$ на основании изложенного выше запишем в виде

$$
\frac{d M}{d t}=\frac{1}{\tau \bar{M}} M\left(\bar{M}+b \mathrm{BB \Pi}_{e x} p_{e x} M-M\right) .
$$

Уравнение для $p_{e x}$ запишем, исходя из положений: с ростом денежной массы $p_{e x}$ растет, но при больших значениях $p_{e x}$ этот рост тормозится. Тогда в простейшем случае уравнение имеет вид

$$
\frac{d p_{e x}}{d t}=\frac{1}{\tau_{e x}}\left(a M-p_{e x}\right)
$$

Здесь параметр $a$ отражает степень роста $p_{e x}$ с возрастанием $M$. Размерность параметра $a-$ обратные «штуки» и по порядку величины $a \approx \frac{p_{i n}}{\bar{M}} \alpha$, где $\alpha-$ безразмерный параметр порядка единицы (но может быть и много меньше), $\tau$ - время установления цен на внешнем рынке.

Введем безразмерные переменные и параметры:

$$
x=M / \bar{M}, \quad y=p_{e x} / p_{i n}, \quad \beta=b p_{i n} \mathrm{BB} \Pi_{e x} .
$$

Время будем измерять в единицах $\tau$.

Тогда уравнения (3) и (4) примут вид

$$
\frac{d x}{d t}=x(1-x+\beta x y), \quad \frac{d y}{d t}=\frac{1}{\tau}(\alpha x-y) .
$$

Фазовый портрет этой системы представлен на рис. 1. Изоклины вертикалей

$$
\left(\frac{d x}{d t}=0\right) x=0, \quad u y=\frac{1}{\beta}\left(\frac{-1}{x}+1\right)
$$

и изоклина горизонталей $\left(\frac{d y}{d t}=0\right)-$ прямая линия: $y=\alpha x$. Пересечения изоклин (стационарные состояния) имеют место при

$$
x=\frac{1}{2 \alpha \beta}(1 \pm \sqrt{1-4 \alpha \beta}) .
$$

При $4 \alpha \beta<1$ существуют два стационарных состояния. Фазовый портрет представлен на рис. 1. Первое состояние - устойчивый узел. Оно соответствует умеренной экспансии доллара, когда дополнительная эмиссия не происходит. Это состояние устраивает всех, кроме США, поскольку сеньёраж при этом тоже практически исчезает.

Второе состояние неустойчиво - седло. Через него проходит сепаратриса, отделяющая область притяжения устойчивого состояния от области безудержного роста долларовой массы и цен, т. е. экономической катастрофы.

При увеличении параметров до $\alpha \beta=1 / 4$ происходит бифуркация - слияние седла с узлом. При $4 \alpha \beta=1+\varepsilon(\varepsilon \ll 1)$ стационарные состояния исчезают, и все фазовое пространство становится областью притяжения катастрофы, что представлено на рис. 2. Однако если $\varepsilon$ мало и изо- 
клины близки друг к другу (открывается так называемое окно возможностей для сеньёража), то изображающая точка движется к катастрофе медленно (по закону $x=\sqrt{\varepsilon} \operatorname{tg} \sqrt{\varepsilon} t$, что создает иллюзию стабильности. Однако с течением времени (когда $\sqrt{\varepsilon} t=\pi / 4$ ) медленное движение переходит в быстрое, и это воспринимается уже как реальная катастрофа.

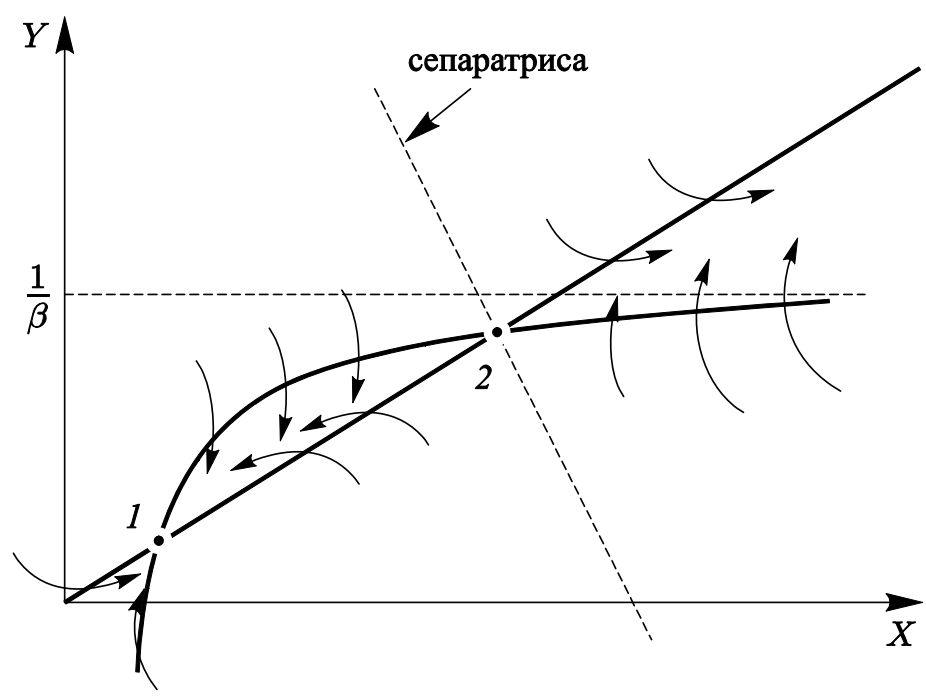

Рис. 1. Фазовый портрет системы уравнений, описывающей использование доллара в качестве международной валюты. $X$ - эмиссия долларов, $Y$ - соотношение внутренних и внешних цен на товары. Существуют два стационарных состояния: 1 - устойчивый узел, 2 - неустойчивое седло. Условия для дополнительной эмиссии (и сеньёража) отсутствуют, так как в этом случае происходит неконтролируемый рост денежной массы (область правее сепаратрисы), т. е. экономическая катастрофа (см. пояснения в тексте) [Чернавский, Щербаков, 2015]

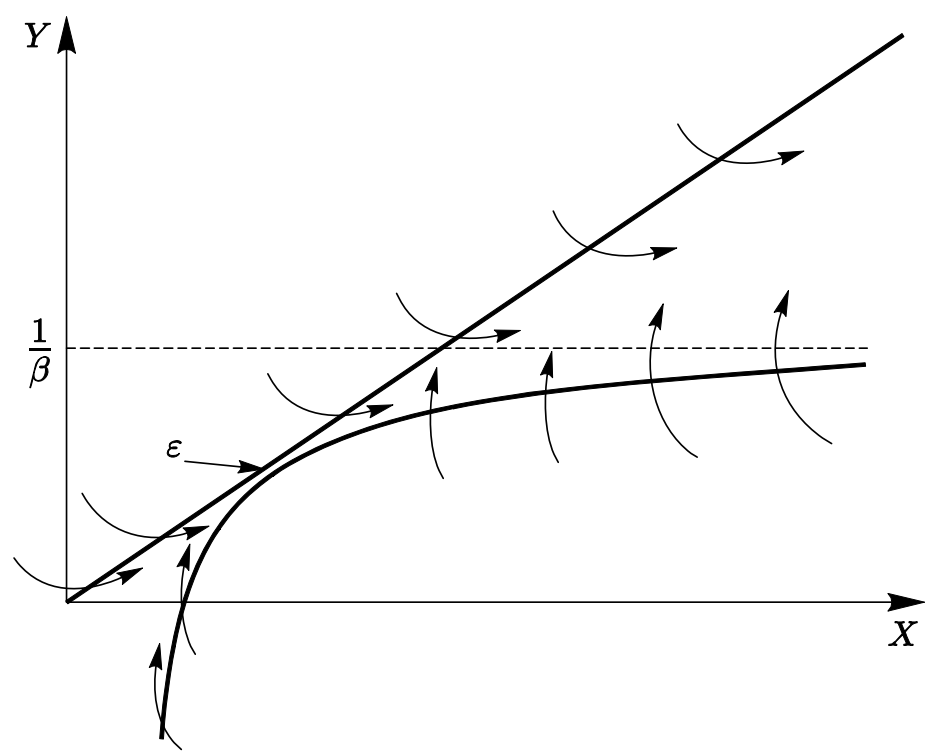

Рис. 2. Фазовый портрет системы уравнений, описывающей использование доллара в качестве международной валюты. $X$ - эмиссия долларов, $Y$ - соотношение внутренних и внешних цен на товары. При изменении параметров системы стационарные состояния исчезают и открывается так называемое окно возможностей $(\varepsilon)$. Появляется возможность дополнительной эмиссии (и сеньёража), при этом экономической катастрофы не возникает, так как система длительное время остается в области «окна» (см. пояснения в тексте) [Чернавский, Щербаков, 2015] 
Таким образом, управляющим параметром (параметром порядка) является произведение $\alpha \beta$ (или в размерных единицах: $\alpha \beta=b a \bar{M}$ ВВП $_{e x}$ ). Эти параметры сами меняются со временем, но медленно. Динамика их изменений определяется не только экономикой, но также политическими и военными факторами. При этом разные страны преследуют разные цели. США стремятся увеличить долларовую экспансию (параметр $b$ ) и одновременно поддержать курс доллара при увеличении $\bar{M}$ (уменьшить параметр $a$ ) с целью получения стабильного сеньёража.

Другие страны стремятся ограничить давление сеньёража. С этой целью они пытаются (где можно) использовать свою валюту в международной торговле (уменьшить ВВП живаемый долларами, и тем самым параметр $\beta$ ). Эти попытки пресекаются политическими (давление США на Евросоюз) и военными (война в Ливии, Ираке и т. п.) методами. В результате управляющий параметр колеблется, оставаясь в среднем постоянным.

По нашим оценкам, упомянутая выше бифуркация уже произошла примерно 20 лет назад, и мир уже встал на путь краха доллара. На это обратил внимание М. Хазин (в чем был прав). Однако он не учел эффект окна возможностей и предсказал немедленное падение курса доллаpa. В течение последних 20 лет происходило медленное движение через «окно», и сейчас мир близок к выходу из него, т. е. быстрому (катастрофическому) падению курса доллара. Последнее может произойти в течение ближайшего года-двух.

Подставив в систему уравнений (5) конкретные макроэкономические параметры, получаем решение, изображенное на рис. 3.

Решение наглядно демонстрирует наличие окна возможностей для доллара в течение 20 лет. По истечении этого срока происходит «катастрофа».

\section{Окно возможностей}

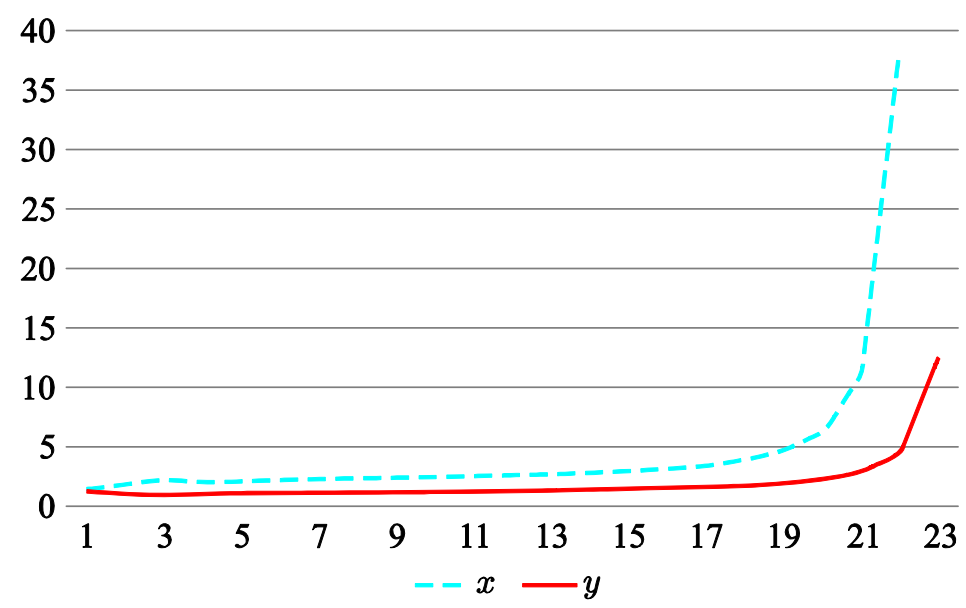

Рис. 3. Решение системы уравнений, описывающей использование доллара в качестве международной валюты. $X$ - эмиссия долларов, $Y$ - соотношение внутренних и внешних цен на товары. По оси абсцисс - время в годах, по оси ординат - значения $X$ и $Y$ в относительных единицах. Система длительное время (20 лет) находится в окне возможностей. Появляется возможность дополнительной эмиссии (и сеньёража), при этом экономическая катастрофа возникает только после прохождения «окна» (через 20 лет (см. пояснения в тексте) [Чернавский, Щербаков, 2015]

\section{II. Динамическая модель закрытого общества (институциональные ловушки и кризисы)}

Вопрос о самоорганизации рыночной экономики в самодостаточной (то есть обеспеченной собственными ресурсами) стране является сейчас одним из актуальных в макроэкономике [Чернавский, Щербаков, Старков, 2015]. Это вопрос - часть более общей проблемы, касающейся взаимодействия нескольких стран с различной экономикой. Он обсуждался многократно 
в работах классиков [Блауг, 1994], с ним связаны направления макроэкономической теории: монетаристское [Fridman, 1968], кейнсианское [Кейнс, 1993], концепция Ларуша [Ларуш, 1997].

Общество - сложная динамическая система. Результаты его эволюции зависят от многих составляющих, среди которых важную роль играет то, каковы условия функционирования экономических субъектов: свободный ли это рынок или рынок с элементами государственного регулирования, авторитарная это система или какая-то их смесь. Но даже если конкретные условия (тип экономики) заданы и, скажем, одинаковы у двух стран, конечные результаты их развития могут оказаться прямо противоположными. Решающая роль в определении результата эволюции, при прочих равных условиях, принадлежит уровню экономического развития общества. Косвенным подтверждением этого может служить наличие множества различных моделей, призванных описать поведение общества и дающих прямо противоположные друг другу результаты. На самом деле между этими моделями нет противоречия, просто они описывают поведение одной и той же сложной системы (рыночная экономика) в разных состояниях и делают это без учета динамического поведения общества и его структуры.

Для решения данной проблемы необходимо опираться на математическую модель динамики процесса. Такой подход развивался за рубежом [Аллен, 1963], но затем интерес к нему ослабел. Сейчас он активно развивается в России и представлен в монографиях [Маевский, 1997; Лебедев, 1997].

Во всех моделях необходимым элементом должно быть описание не только стационарных состояний, но и переходных процессов, которые сейчас являются наиболее актуальными, поскольку именно с ними связано поведение государств, испытывающих кризис.

Мы обратим внимание на два обстоятельства, которые, как нам кажется, могут играть важную роль в формировании кризисных процессов.

Во-первых, в большинстве современных экономических моделей, претендующих на количественное описание, явно или неявно предполагается существование единственного устойчивого равновесного состояния, при отклонении от которого общество возвращается к нему под влиянием рыночных процессов или регулирования. При этом не учитывается тот факт, что в реальном рыночном обществе могут существовать несколько равновесных состояний с различными экономическими показателями. Среди них могут быть и неблагополучные. Последние получили название «институциональные ловушки» [Полтерович, 1998]. Отметим, что классики экономики хорошо понимали это обстоятельство, хотя и не могли описать его на математическом языке [Робинсон, 1986; Хикс, 1988], однако затем оно было забыто, интерес к нему появился лишь в последнее время. Выведение общества из одного состояния устойчивого равновесия может перевести его в такую область, откуда оно будет стремиться к другому равновесному состоянию. Более того, даже плавное изменение макроэкономических показателей общества может приводить к тому, что прежнее равновесное состояние исчезнет, и тогда общество заведомо будет стремиться к другой точке равновесия, находящейся, может быть, очень далеко от предыдущей. В обоих случаях такие, внешне кажущиеся неожиданными, процессы воспринимались бы как кризис или экономическое чудо.

Во-вторых, как показано в целом ряде работ [Чернавский и др., 1995; Чернавский и др., 1996; Чернавский и др., 1998], на динамическое поведение общества существенное влияние оказывает экономическая структура общества (ЭСО). Под ЭСО мы понимаем распределение элементов общества (семей) по ликвидным накоплениям. Она играет важную роль в балансе спроса и предложения на товары, услуги, финансы и т. д. В традиционных макроэкономических моделях на количественном уровне, как правило, рассматриваются только одна группа потребителей и одна группа производителей, формирующих спрос и предложение. Пересечение соответствующих кривых, например в координатах «цена-объем», определяет значение равновесной величины макроэкономического показателя. Такой подход фактически означает замену рассмотрения распределенных величин спроса и предложения на рассмотрение соответствующих средних. Эта замена с математической точки зрения правомерна для распределений близких к нормальному и вблизи положения равновесия. Если система находится вдали от точки равновесия или распределение существенно отличается от нормального, например является 
двугорбым, как в современной России, ограничение рассмотрения только анализом средних величин может привести к неверным значениям макроэкономических показателей, отличающимся на порядки величин от действительных, а динамика поведения реального общества может качественно отличаться от модельного.

Два приведенных выше замечания особенно важны для обществ, находящихся в состоянии кризиса и/или реформирования, поскольку именно в эти периоды макроэкономические показатели претерпевают значительные изменения, а имущественное расслоение общества увеличивается. Примером такого общества является, в частности, Россия.

До сих пор были рассмотрены только незамкнутые варианты модели, в которых не учитывалось влияние производства и товарооборота на ЭСО [Чернавский и др., 1995; Чернавский и др., 1996; Чернавский и др., 1998]. Рассмотрим простейшую модель, в которой только через механизм взаимодействия спроса и предложения учитывается как прямая, так и обратная связь процессов производства-потребления и ЭСО. Такая модель позволяет ответить на представленные ниже вопросы.

1. Существует ли стационарное состояние общества? Если существует, то единственно ли оно и при каких условиях устойчиво?

2. Какова стационарная структура общества (унимодальна или бимодальна), как она зависит от продуктивности и как последняя зависит от нее?

Рассматривается вариант закрытого общества, в котором экспорт и импорт товара отсутствует.

\section{Основные положения модели}

1. Рассматриваются производство и потребление одного продукта (так называемое однопродуктовое приближение). Его можно рассматривать как стандартную совокупность товаров, в которой коэффициенты предпочтения зафиксированы и одинаковы для всех слоев общества.

При этом в процессе обмена деньги фактически жестко связаны с продуктом, поэтому экономические показатели, такие как прибыль, объем производства и потребления и т. п., можно исчислять как в денежных, так и в натуральных (штуках, килограммах и т. д.) единицах. Действительно, деньги, как универсальный товар, играют особую роль, только если число различных товаров велико. В этом случае прямой обмен приводит к проблеме факториальной сложности, для преодоления которой, собственно, и были введены деньги. В процессе же потребления роль денег и товаров различается, так как потребление товаров приводит, а потребление денег не приводит к их выбыванию из обращения.

Цену продукта в дальнейшем будем обозначать как $p$.

2. Рассматривается общество, состоящее из двух групп.

I. Производители (работники), число которых обозначим как $n^{\prime}$, работающие на предприятиях собственников. В их число мы включим не только непосредственных производителей, но также обслуживающий персонал и служащих, занятых в инфраструктуре, охране и поддержании стабильности всего общества. Все они объеденены тем, что их доход - зарплата $P_{n}$, отличная от доходов второй группы.

II. Организаторы (они же собственники, владельцы), число которых обозначим как $m^{\prime}$, получающие доход от продажи произведенного на их предприятиях товара и выплачивающие зарплату $P_{n}$ членам первой группы. Доходы собственников обозначим как $P_{m}$. В их число включены также посредники и торговцы, живущие за счет прибыли, но не зарплаты.

Накопления семей первой и второй групп обозначим как $U_{n^{\prime}}$ и $U_{m^{\prime}}$ соответственно.

Доходы и накопления членов разных групп различны, но внутри каждой группы будем считать их одинаковыми.

В такой модели ЭСО представляется в виде двух узких пиков (горбов). Реально горбы размыты, и если расстояние между ними больше их ширины, то ЭСО бимодально. Если горбы близки, то общество практически унимодально. 
В модели структура общества зависит от двух параметров: относительной численности $\sigma=n / m$ и отношения доходов $D=P_{m} / P_{n}$ (или накоплений $U_{m} / U_{n}$ ). Последнее отражает относительное расстояние между горбами, то есть модальность общества.

3. Примем, что необходимые для производства ресурсы (полезные ископаемые, посевные площади и т. п.) находятся в избытке. При этом можно считать, что безработные в обществе отсутствуют. Отсюда следует, что рынок труда в модели фактически отсутствует. При этом численности $n^{\prime}$ и $m^{\prime}$ определяются не балансом на рынке труда, а экономической целесообразностью, зависящей от уровня технологии производства и его организации. Далее это отношение будем считать заданным.

4. Будем считать, что объем денег в обществе равен $M$, а количество семей равно $N$, причем числа $M$ и $N$ фиксированы. Таким образом справедливы «законы сохранения» людей $\left(n^{\prime}+m^{\prime}=N\right)$ и денег $\left(n^{\prime} U_{n}+m^{\prime} U_{m}=M\right)$. Далее удобно использовать относительные численности $\left(n=n^{\prime} / N\right.$ и $\left.m=m^{\prime} / N\right)$ и относительные накопления (покупательные способности накоплений: $r_{n}=U_{n} / p$ и $\left.r_{m}=U_{m} / p\right)$. Тогда законы сохранения можно представить в виде

$$
n+m=1, \quad n U_{n}+m U_{m}=\bar{U}=M / N, \quad n r_{n}+m r_{m}=\bar{U} / p=\bar{r},
$$

где $\bar{U}$ - средние накопления и $\bar{r}$ — относительные средние накопления.

5. В дальнейшем важную роль будет играть функция производства $\bar{F}(n, S)$, то есть количество продукта (в естественных единицах, например в штуках), производимое в обществе в единицу времени. Оно зависит от числа производителей $N n$ и от капиталовложений $S . \mathrm{B}$ нашей модели функция производства обладает следующими свойствами.

i) Она пропорциональна числу производителей, то есть

$$
\bar{F}(n, S)=N n F(S) .
$$

Здесь $F(S)$ - удельная производительность труда, т. е. выработка, приходящаяся на одного работника в единицу времени.

ii) Капиталовложения (производственные затраты) зависят от накоплений в обществе. В первую очередь их делают владельцы, и их объем зависит от накоплений $r_{m}$. Накопления служащих также могут быть использованы для инвестиций через банковскую систему. В этом случае доходы последних, помимо зарплаты, включают проценты по вкладу. Однако, в данной работе мы не будем учитывать эту взаимосвязь, то есть примем, что банковская система и рынок денег отсутствуют ${ }^{1}$. Далее будем инвестиции исчислять в реальных единицах и считать, что они зависят от реальных накоплений $r_{m}$. С ростом накоплений вложения увеличиваются. Примем в первом приближении, что вложения пропорциональны накоплениям.

В однопродуктовой модели все затраты владельцев в конце концов идут на зарплату рабочих. К ним относятся непосредственные участники производства, ремонтные рабочие, а также все рабочие и служащие бюджетной сферы (транспорт, правоохранительные органы и т. д.). Далее будем считать, что их зарплата одинакова и соотношения их численностей заданы.

iii) Производительность труда растет с ростом затрат, но не может быть больше некоторой величины $F_{\max }$, определяемой уровнем техники. Примем, что производственная функция имеет кусочно-линейный характер:

$$
F(s)= \begin{cases}g r_{m}, & F<F_{\text {max }}, \\ g r_{c r}, & F=F_{\text {max }} .\end{cases}
$$

Здесь $r_{c r}=F_{\max } / g$ - величина накоплений, выше которой прямые вложения в производство не приводят к росту выпуска товара.

\footnotetext{
${ }^{1}$ Кстати, это допущение не так уж далеко от реальной ситуации в современной России.
} 
iv) Капиталовложения $S$ в нашей модели пропорциональны объему производства: $S=$ $=n \cdot s=n / b \cdot F$. Здесь $s$ - капиталовложения (в штуках товара), приходящиеся на одного работника в единицу времени. Коэффициент $b>1$ отражает уровень рентабельности, равный $(b-1) \cdot 100 \%$.

6. Функцию потребления продукта обозначим как $Q(p, U)$. Здесь $U-$ накопления семьи, а $Q$ - количество продукта, приобретаемого за цену $p$ при накоплениях $U$ в единицу времени. В силу масштабной инвариантности функция $Q(p, U)$ зависит от отношения $r=U / p$, т. е. от покупательной способности накоплений.

В нашей модели функция потребления $Q(r)$ зависит от трех параметров, качественно характеризующих ее поведение. Она ограничена сверху максимальными потребностями в продукте в единицу времени: $Q(r)<Q_{0}$. Другой важный параметр - положение точки перегиба. По смыслу этот параметр задает отношение накоплений к цене, при котором люди начинают активно приобретать товар. Третий параметр - ширина переходной области, где люди приобретают товар, но не могут удовлетворить свои потребности в нем полностью. Мы представим $Q(r)$ в виде

$$
Q(r)=Q_{0} \frac{r^{v}}{r_{0}^{v}+r^{v}} .
$$

Положение точки перегиба определяется параметром $r_{0}$, а ширина переходной области зависит от параметра $v$.

При $v=1$ функция $Q(r)$ всюду выпукла, что характерно для товаров первой необходимости. При $v \geq 2$ функция потребления имеет сигмоидную форму, что характерно для промышленных товаров долговременного пользования. При $v \gg 1$ ширина переходной области стремится к нулю, и функция приобретает пороговый характер. В расчетах, приведенных в данной работе, мы приняли $v=2$.

Кроме основной зависимости, описываемой формулой (9), мы учтем наличие товаров различного качества и возникающее по этой причине возрастание потребностей при росте накоплений, введя дополнительный член $\varepsilon \cdot r$. Таким образом,

$$
Q(r)=\frac{r^{v}}{r_{0}^{v}+r^{v}}+\varepsilon r .
$$

7. Зарплата $P_{n}$ в натуральных единицах, которую производители получают от владельцев в единицу времени, зависит от капиталовложений. В силу сохранения общего объема денег ее величина равна капиталовложениям. Таким образом, $P_{n}=s$ :

$$
P_{n}=\left\{\begin{array}{cc}
h \cdot r_{m}, & r_{m}<r_{c r}, \\
b^{-1} F_{\max }, & r_{m} \geq r_{c r} .
\end{array}\right.
$$

Здесь нами введен параметр $h=g / h$, который показывает долю накоплений собственников, выделяемую в виде капиталовложений $S_{v}$ при $r_{m}<r_{c r}$ на одного работника в единицу времени. Зарплата в денежном выражении равна $P_{n} \cdot p$.

\section{Формулировка модели}

Динамику общества мы будем описывать зависящими от времени переменными. В качестве таковых мы используем:

1) накопления «служащих» $U_{n}$;

2) количество продуктов, хранящихся на складах (эту величину мы обозначим как $R$ );

3) цену товара $p$. 
Динамика накоплений $U_{n}$ определяется балансом доходов и расходов членов первой группы:

$$
\frac{d U_{n}}{d t}=\left(P_{n}-Q\left(r_{n}\right)\right) p
$$

Величина $U_{m}$ не является независимой переменной и определяется из закона сохранения денег (6):

$$
U_{m}=\frac{\bar{U}-n U_{n}}{m}
$$

Здесь уместно сделать замечание. Динамика доходов и расходов в натуральных единицах определяется уравнением, отличным от уравнения (11), и имеет вид

$$
\frac{d r_{n}}{d t}=P_{n}-Q\left(r_{n}\right)=\frac{1}{p} \frac{d U_{n}}{d t}-\frac{r_{n}}{p^{2}} \frac{d p}{d t}
$$

откуда получаем

$$
\frac{d U_{n}}{d t}=p\left(P_{n}-Q\left(r_{n}\right)\right)+\frac{r_{n}}{p} \frac{d p}{d t} .
$$

Последнее слагаемое правой части соответствует индексации зарплаты при ценовой инфляции, но без дополнительной эмиссии денег (величину $M$ мы полагаем постоянной). Мы будем считать, что владельцы без принуждения такой индексации не проводят.

Другая независимая переменная - запасы продукта $R$. Динамика запасов определяется балансом поступлений продуктов на склад и реализацией их на рынке [Аллен, 1963]:

$$
\frac{d R}{d t}=\gamma \cdot\left[n F\left(r_{m}\right)-\mathfrak{I}(R)\right]
$$

Здесь $\Im(R)$ - количество продуктов, поступающих на рынок в единицу времени; $\gamma$ - безразмерный коэффициент, характеризующий быстроту отслеживания складом ситуации на рынке.

Третьей независимой переменной является цена $p$. Динамика цены определяется балансом спроса и предложения:

$$
\frac{d p}{d t}=\alpha \cdot N\left[n Q\left(r_{n}\right)+m Q\left(r_{m}\right)-\Im(R)\right]=\alpha \cdot N \cdot \operatorname{dis} .
$$

Здесь $d i s=\left[n Q\left(r_{n}\right)+m Q\left(r_{m}\right)-\mathfrak{I}(R)\right]-$ дисбаланс предложения и спроса. Величина $N \cdot\left[n Q\left(r_{n}\right)+m Q\left(r_{m}\right)\right]$ представляет собой платежеспособный спрос, и $N \cdot \mathfrak{I}(R)-$ объем предложения. Обе величины выражены в естественных единицах товара, потребляемого или предлагаемого в единицу времени, которая соответствует времени потребления (или амортизации) товара $\tau_{q}$. Обычно таковым считается год, что в случае производства сельхозпродукции оправданно. Изменение цены в единицу времени выражается в рублях за единицу товара и за характерное время установления рыночного равновесия $\tau_{p}$. Последняя заметно меньше времени цикла потребления.

Коэффициент $\alpha$ содержит отношение времен $\tau_{p} / \tau_{q}$ и имеет следующую размерность: $(\text { единица товара })^{-2} \cdot$ руб. Его можно представить как комбинацию величин:

$$
\alpha \propto \frac{\alpha^{\prime}}{\tau_{q}} \cdot p_{0} \frac{1}{Q_{0}} .
$$

Здесь $p_{0}$ - эффективная цена, $Q_{0}-$ потребление в единицу времени, $\alpha^{\prime}-$ безразмерный параметр порядка единицы. 
Сделаем несколько замечаний.

i. В (15) принято, что динамика цен пропорциональна дисбалансу спроса и предложения. В действительности зависимость может быть более сложной, но она должна быть нечетной по дисбалансу так, чтобы знак дисбаланса совпадал со знаком производной. В (15) выбран один из простейших вариантов.

ii. В (15) дисбаланс выражен в естественных единицах. Возможен вариант, когда цены реагируют на дисбаланс в денежном выражении, Тогда (15) примет вид $\frac{d p}{d t}=\alpha_{1} \cdot N \cdot p \cdot d i s$. В обоих случаях стационарные состояния соответствуют условию $d i s=0$ и топологическая структура решений модели будет одна и та же, но динамика стремления к стационарному состоянию будет несколько различаться. В данной работе мы ограничимся моделью (15).

Далее будем считать, что ситуация на рынке отслеживается складом достаточно быстро (т. е. $\gamma \gg 1)$. Тогда переменная $R$ быстро приходит к своему стационарному значению, и на основе теоремы Тихонова уравнение (14) можно заменить соотношением $\Im(R)=n F\left(r_{m}\right)$. В этом приближении конкретный вид функции $\Im(R)$ уже не важен. Уравнение (15) при этом примет вид

$$
\frac{d p}{d t}=\alpha N\left[n Q\left(r_{n}\right)+m Q\left(r_{m}\right)-n F\left(r_{m}\right)\right]
$$

Обсудим смысл уравнений (11) и (16).

Уравнение (11) показывает, что спрос производителей удовлетворяется в соответствии с их запросами $n Q\left(r_{n}\right)$. В уравнении (12), с другой стороны, видно, что и запросы собственников удовлетворяются полностью в соответствии с их накоплениями. Таким образом, в нашей модели платежеспособный спрос потребителей на товары всегда удовлетворяется.

В рассматриваемом варианте модели производственная функция при малых накоплениях собственников пропорциональна $r_{m}$. Это означает, что собственники выделяют средства на производство при любой (даже самой малой) величине накоплений. Более последовательной была бы модель, в которой выделение средств на производство происходит только при $r_{m}>r_{c r}>0$. При $r_{m}<r_{c r}$ В этой модели могло бы происходить уменьшение расходов за счет их полного прекращения.

Связь уравнения (14) с другими моделями установления цены (основанными на принципе максимума прибыли) мы обсудим ниже.

Для дальнейшего рассмотрения удобно ввести безразмерные переменные:

$$
x=U_{n} / \bar{U}, \quad y=p / p_{0}, \quad r_{n}^{\prime}=r_{n} / r_{0}, \quad r_{m}^{\prime}=r_{m} / r_{0}, \quad h^{\prime}=h / Q_{0} .
$$

Здесь $p_{0}=\bar{U} / r_{0}$. (Далее штрихи опустим, то есть будем считать, что $r_{0}=1$ и $Q_{0}=1$.)

Величины $r_{n}$ и $r_{m}$, согласно (6), (12) и (17), зависят от $x$ и $y$ :

$$
r_{n}=\frac{x}{y}, \quad r_{m}=\frac{1-n x}{m y}
$$

Уравнения (11) и (15) в переменных $x$ и $y$ принимают вид

$$
\begin{gathered}
\frac{d x}{d t}=h \frac{1-n x}{m}-y Q\left(\frac{x}{y}\right) \\
\frac{d y}{d t}=\alpha N\left[n Q\left(\frac{x}{y}\right)+m Q\left(\frac{1-n x}{m y}\right)-n F\left(\frac{1-n x}{m y}\right)\right] .
\end{gathered}
$$


Рассмотрим сперва стационарные состояния, в которых $d x / d t=0\left(d U_{n} / d t=0\right)$ и $d y / d t=0$ $(d p / d t=0)$. Это удобнее сделать в переменных $r_{n}$ и $r_{m}$. При $r_{m}<r_{c}$, согласно (12) и (17) $h \cdot r_{m}=Q\left(r_{n}\right)$ и $n Q\left(r_{n}\right)+m Q\left(r_{m}\right)=n g r_{m}$, откуда следует, что стационарные значения переменной $r_{m}$ удовлетворяют уравнению

$$
n(g-h) r_{m}=m Q\left(r_{m}\right)
$$

или

$$
Q\left(r_{m}\right)=q r_{m},
$$

где $q=n / m(g-h)$.

Решениями уравнения (21) являются точки пересечения функции $Q\left(r_{m}\right)$ и прямой линии $q r_{m}$. Эти точки приведены на рис. 4 , где обозначены как $r_{m, 1}$ и $r_{m, 2}$ соответственно. Отметим, что состояние $r_{m, 1}$ устойчиво, а состояние $r_{m, 2}$ неустойчиво. Значение $q=0.5$ в (21) является бифуркационным: при этом значении $q$ прямая $q r_{m}$ касается кривой $Q\left(r_{m}\right)$.

При $r_{m}>r_{c r}$ условие стационарности приводит к уравнению (22):

$$
Q\left(r_{m}\right)=n / m \cdot F_{\max }\left(1-b^{-1}\right) .
$$

Это уравнение дает третью точку пересечения, обозначенную на рис. 4 как $r_{m, 3}$.

Наконец, точке $r_{m}=0$ тоже соответствует стационарное состояние, в котором отсутствуют как производство, так и потребление товара; иными словами, это состояние - глубокий кризис общества. К счастью, оно неустойчиво.

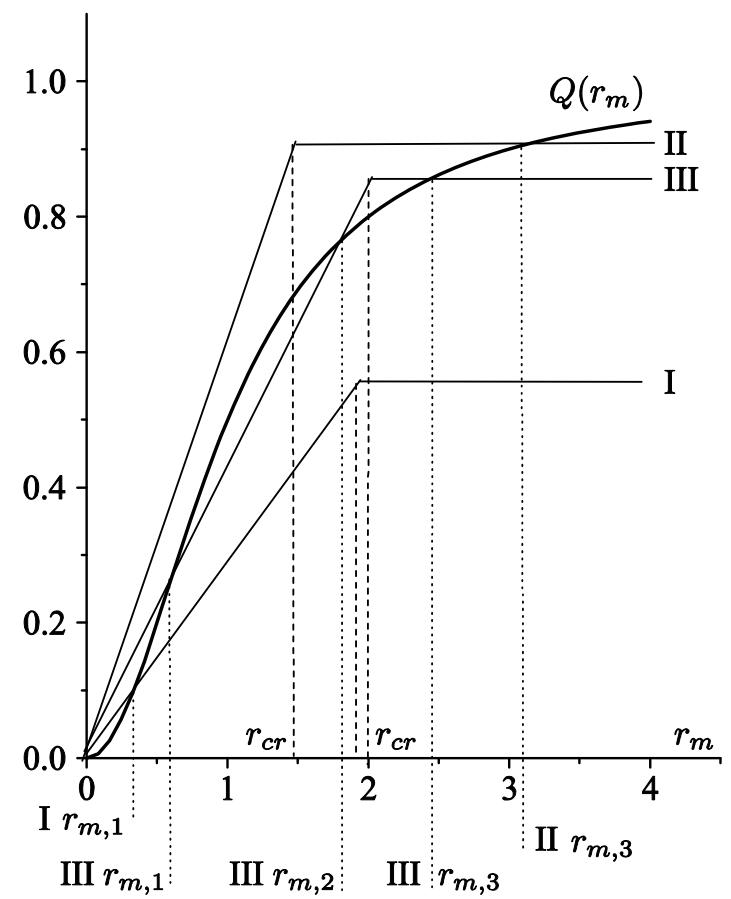

Рис. 4. Решения бифуркационного уравнения $Q\left(r_{m}\right)=q \cdot r_{m}$ (при $\left.r_{m}<r_{c r}\right)$ и $Q\left(r_{m}\right)=n / m \cdot F_{\max } \cdot\left(1-b^{-1}\right)$ (при $r_{m}>r_{c r}$ ), то есть пересечения функции потребления $Q\left(r_{m}\right)$ и производственной функции $F$. По оси абсцисс - накопления владельцев $\left(r_{m}\right)$, по оси ординат - количество товара (в относительных единицах). Существует три варианта решения: I (пересечение функций I и $\left.Q\left(r_{m}\right)\right)$ - I $r_{m, 1}$ (устойчивое низкопродуктивное состояние общества); II (пересечение функций II и $\left.Q\left(r_{m}\right)\right)$ - II $r_{m, 3}$ (устойчивое высокопродуктивное состояние общества); III (пересечение функций III и $\left.Q\left(r_{m}\right)\right)$ - III $r_{m, 1}$ (устойчивое низкопродуктивное состояние общества), III $r_{m, 2}$ (неустойчивое седло), III $r_{m, 3}$ (устойчивое высокопродуктивное состояние общества). Величины $r_{c r}$ определяют значения $r_{m}$, при которых достигается максимальный объем производства (см. пояснения в тексте) [Чернавский, Щербаков, Старков, 2015] 
В зависимости от значений параметров (точнее, от их комбинаций) возможны следующие варианты, представленные на рис. 4.

I. При $0<n / m(g-h)<0.5$ существует устойчивое состояние типа $r_{m, 1}$, при котором потребности удовлетворены далеко не полностью.

II. При $n / m(g-h) r_{c r}>Q\left(r_{c r}\right)$ существует устойчивое состояние типа $r_{m, 3}$, при котором потребности владельцев удовлетворены практически полностью. Знак равенства в этом выражении соответствует точке бифуркации. При этом точка пересечения прямых в правых частях выражений (21) и (22) лежит на кривой $Q\left(r_{m}\right)$. Так как величина $r_{c r}$ обычно достаточно велика, $Q\left(r_{c r}\right)$ в вышеприведенном неравенстве можно приближенно заменить на 1 . Тогда условие существования устойчивого состояния типа $r_{m, 3}$ запишется в виде $n / m(g-h)>1 / r_{c r}$.

III. При выполнении обоих неравенств, $0.5>n / m(g-h)>1 / r_{c r}$, существуют устойчивые состояния обоих типов.

Таким образом, в системе уравнений (19), (20) возможны бифуркации (внезапное исчезновение одного из устойчивых состояний) двух типов и два бифуркационных параметра: $F_{\max }$ и $q=n / m(g-h)$.

\section{Динамика процессов}

Диаграмма рис. 4 не дает ответа на вопрос о поведении системы в нестационарных условиях. Для ответа на этот вопрос удобнее использовать переменные $x$ и $y$ и динамические уравнения (19) и (20).

На рис. 5 приведен фазовый портрет в случае, когда параметры соответствуют варианту III. Видно, что имеются два устойчивых состояния, 1 и 3 , состояние 2 неустойчиво. Фазовая плоскость разделена сепаратрисой (жирный пунктир). Значения параметров и основные свойства стационарных состояний приведены на рисунках.

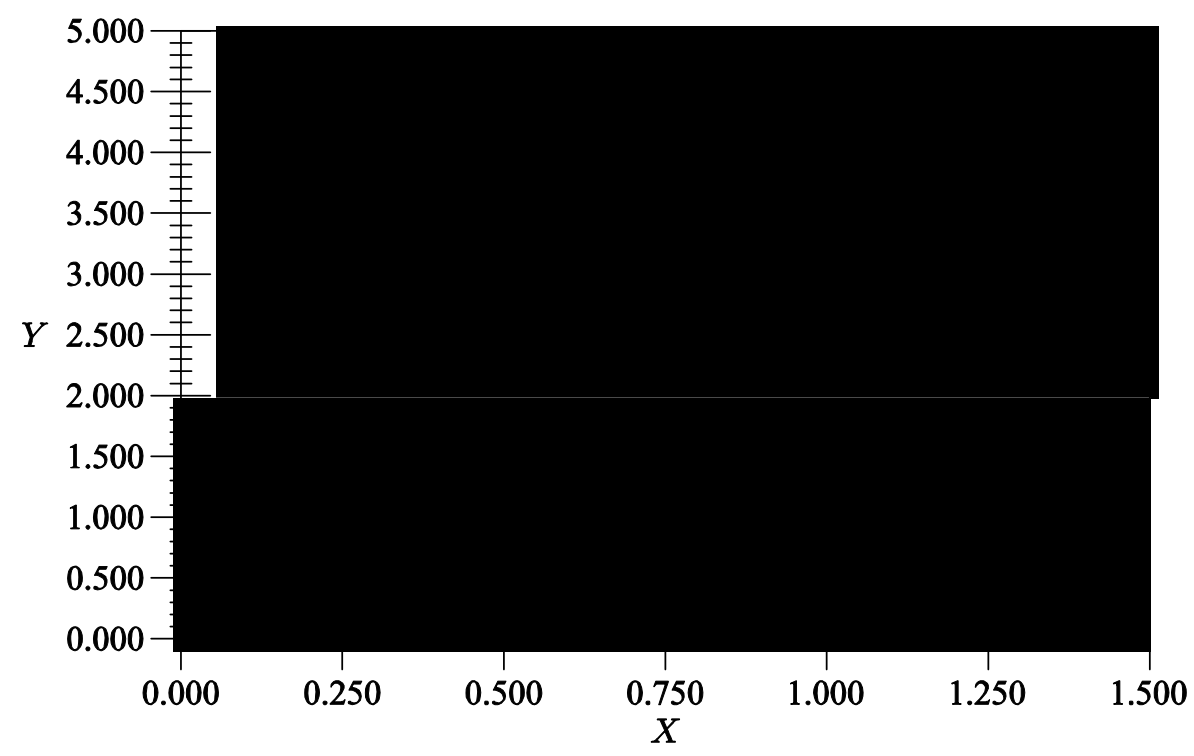

Рис. 5. Фазовый портрет системы уравнений, описывающей замкнутое общество в однопродуктовом приближении. По оси абсцисс - накопления работников, по оси ординат - цена товара (в относительных единицах). Жирные линии - изоклины $d x / d t=0$ и $d y / d t=0$. Точки пересечения изоклин определяют стационарные состояния ( 1 и 3 - устойчивые, 2 - неустойчивое). Тонкие линии - траектории эволюции общества. Каждой точке траектории соответствует определенное значение времени. Эволюция общества начинается с краев рисунка и заканчивается в точках стационарного состояния. Штриховая линия - сепаратриса. Значения параметров: $h=0.15, b=2.8, F_{\max }=1, \alpha N=2, \varepsilon=0.1$ (см. пояснения в тексте) [Чернавский, Щербаков, Старков, 2015] 
На рис. 5 в состоянии 1 потребности как рабочих так и владельцев удовлетворены на низком уровне $\left(Q\left(r_{n}\right)=0.05, Q\left(r_{m}\right)=0.3\right)$. В состоянии 3 потребности удовлетворены полностью. Поляризация общества (величина $D$ ) невелика. Из этого примера следует, что при одинаковых условиях (параметрах модели) можно попасть как в благополучный режим (состояние 3 ), так и в близкий к кризисному (состояние 1 ). Результат зависит от начальных условий и от управляющих воздействий на систему на пути ее движения по траектории (последние изображены бледным пунктиром). Управляющие воздействия могут быть как параметрическими (временное изменение параметров) так и силовыми (изменения накоплений и/или цен за счет внешних факторов).

\section{Целевые функции владельцев}

При фиксированных параметрах $h, b$ и $F_{\max }$ эволюция общества под управлением уравнений (19) и (20) происходит автоматически. Участники рынка не влияют на этот процесс, в частности у них отсутствует цель, преследуя которую они могли бы делать выбор среди разных потенциально возможных путей развития общества. В реальности же поведение участников рынка может опираться не только на текущие величины спроса и предложения, учтенные в (19) и (20), но и на ожидания, связанные с будущими величинами прибыли (краткосрочные цели), накоплений (долгосрочные цели) или с чем-то иным. Рассмотрим в связи с этим несколько вариантов реализации целевых функций собственников, анализ которых на качественном уровне возможен в рамках нашей модели.

1. Целевая функция - максимизация прибыли в натуральном выражении (дальновидная стратегия).

В равновесном состоянии прибыль собственников определяется разностью между средствами, полученными от реализации произведенной продукции, и затратами на ее изготовление:

$$
m \Pi_{1}=m Q\left(r_{m}\right)+n Q\left(r_{n}\right)-n P_{n} .
$$

В стационарном состоянии согласно условию $d x / d t=0$ два последних слагаемых дают нулевой вклад. Поэтому прибыль будет равна расходам собственников на собственное потребление: $\Pi_{1}=Q\left(r_{m}\right)$, а ее максимизация соответствует максимизации стационарного значения накоплений $r_{m}$ как функции управляющих параметров.

В стационарном состоянии $l$ величину $r_{m}$ можно выразить в виде

$$
r_{m}=\left[1-\sqrt{\left(1-4 q^{2}\right)}\right] / 2 q .
$$

Для достижения цели необходимо изменять параметры $b$ и $h$ так, чтобы увеличить $q$. Накопления рабочих в состоянии 1 равны

$$
r_{n}=\sqrt{\frac{r_{m}}{\left(1-h r_{m}\right)}} .
$$

Видно, что они также возрастают с ростом $r_{m}$, то есть дальновидные интересы владельцев и рабочих совпадают. Максимальное значение $r_{m}$ в состоянии 1 достигается при $q=0.5$. Однако при этом состояние 1 исчезает, и общество само устремляется к состоянию 3 , и благосостояние всех слоев общества быстро возрастает. Такая бифуркация воспринимается как «экономическое чудо».

В состоянии $3 r_{m}$ хотя и велико, но $Q\left(r_{m}\right) \approx \varepsilon \cdot r_{m}$, где величина $\varepsilon \ll 1$. Поэтому небольшое изменение параметров мало влияет на величину прибыли $\Pi_{1}$, а приводит в основном к изменению величин издержек, в том числе на выплату зарплаты.

2. Целевая функция - максимизация прибыли в денежном выражении (монетаристская стратегия). В этом случае прибыль равна величине прибыли $\Pi_{1}$, умноженной на цену: $\Pi_{2}=\Pi_{1} y$. 
Из (18) и (23) можно получить выражение

$$
n_{2}=\frac{r_{m}^{2}}{1+r_{m}^{2}} \cdot \frac{1}{n r_{n}+m r_{m}} .
$$

С учетом (24) можно показать, что в состоянии 1 максимальная величина $\Pi_{2}$ достигается при некотором значении $r_{m}$ в интервале $0<r_{m}<1 / h^{\prime}$. Выражение для этого значения довольно громоздко, и мы его здесь не приводим.

В состоянии 3 в приближении $Q\left(r_{m}\right) \approx \varepsilon \cdot r_{m}$ накопления можно записать в виде

$$
r_{n}=\sqrt{\frac{n F_{\max }-m}{1-n F_{\max }}}, r_{m}=\left[\left(1-b^{-1}\right) F_{\max }-m / n\right] / \varepsilon .
$$

В этом случае также существует конечная величина $r_{m}$, максимизирующая величину $\Pi_{2}$. Ее значение равно единственному действительному корню уравнения $r_{m}{ }^{3}-r_{m}-2 B=0$ :

$$
r_{m}=\sqrt[3]{B+\sqrt{B^{2}-8 / 27}}+\sqrt[3]{B-\sqrt{B^{2}-8 / 27}} .
$$

Здесь $B=n r_{n} / m$. Таким образом, собственники могут максимизировать величину $\Pi_{2}$, подбирая параметр $b$ в соответствии с (26). Так как величина $r_{n}$ зависит только от $F_{\max }$, действия собственников в этом случае не влияют на величину накоплений рабочих.

Следует отметить, что фазовый портрет в случае оптимизированных стационарных состояний ничем не отличается от случаев с неоптимизированными состояниями. Более того, на рис. 5 в точке 3 реализуется максимум $\Pi_{2}$.

3. Целевая функция - социальный комфорт в обществе. Под социальным комфортом общества будем понимать отсутствие дифференциации общества по накоплениям. Будем характеризовать его отношением $\Pi_{3}=r_{n} / r_{m}$.

В состоянии 1 в соответствии с (24) имеем

$$
n_{3}=\frac{1}{r_{m}} \sqrt{\frac{h r_{m}}{1-h r_{m}}} .
$$

Это выражение имеет минимум $\Pi_{3}=2 h$ при $r_{m}=0.5 / h$ и неограниченно растет при $r_{m}$, стремящемся к 0 и к $1 / h$. Однако, так как в состоянии $1, r_{m}<1$ и $h<1$, минимум и второй предел не реализуются. Оптимальная величина $\Pi_{3}=1$ достигается при выполнении равенства $h=q$.

В состоянии 3 величина $\Pi_{3}$ определяется отношением выражений в (26). Так как в этом случае $r_{n}$ не зависит от управляющих параметров $h$ и $b$, оптимизация целевой функции может быть осуществлена только за счет изменения $r_{m}$. Из (26) следует, что при уменьшении (увеличении) $b$ целевая функция Пз увеличивается (уменьшается), а от параметра $h$ она не зависит. Значение $\Pi_{3}=1$ достигается при выполнении равенства

$$
\left[\left(1-b^{-1}\right) F_{\max }-m / n\right] / \varepsilon=\sqrt{\frac{n F_{\max }-m}{1-n F_{\max }}} .
$$

Таким образом, регулируя управляющие параметры, собственники могут добиваться реализации экстремума той или иной целевой функции. Стоит оговориться, что данный результат получен в условиях отсутствия ограничений по ресурсам.

Изложенное можно прокомментировать следующим образом. Цель - максимизация прибыли в денежном выражении, представляется более естественной, но менее дальновидной. Если преобладает эта цель, то неблагополучное состояние (1) устойчиво по отношению к вариации параметров, следовательно, общество может пребывать в нем достаточно долго. Поляризация при этом невелика, и социальный дискомфорт отсутствует.

Цель - максимизация прибыли в реальном выражении, более дальновидная. Для достижения этой цели необходимо увеличивать параметр $b$ за счет уменьшения $h$ либо за счет увели- 
чения $g$. И то и другое сводится к увеличению затрат на производство. При этом реальные накопления обеих групп растут, но денежные доходы падают. Последнее создает препятствие, хотя и чисто психологическое. При движении к этой цели состояние 1 может стать неустойчивым, и тогда общество быстро перейдет в область более благополучного состояния 3. Такой скачок воспринимается как очередное «экономическое чудо», а руководители государства этого периода - как благодетели нации.

\section{Влияние денежной эмиссии на состояние общества}

До сих пор мы рассматривали влияние параметрического воздействия на систему. Обсудим теперь на качественном уровне возможность силового управляющего воздействия на примере денежной эмиссии. Рассмотрим общество, имеющее два устойчивых состояния (1 и 3 ) и находящееся в состоянии 1 . Поставим перед собой цель: перевести общество в состояние 3. Для этого необходимо произвести действия, при которых начальное состояние общества оказалось бы ниже сепаратрисы в плоскости $X-Y$. Попробуем добиться этого с помощью денежной эмиссии. Допустим, что количество денег в обществе меняется с $M$ до $M^{\prime}$, причем $M^{\prime}>M$. В соответствии с (6) это означает увеличение размера средних накоплений $\bar{U}^{\prime}>\bar{U}$ в $W=M^{\prime} / M$ раз. Дальнейшая реакция системы зависит от направленности эмиссии, то есть от ее адресности.

Рассмотрим вначале эмиссию, адресованную собственникам, то есть направленную на расширение производства и спроса собственников. В этом случае накопления работников в денежном выражении останутся неизменными: $U_{n}^{\prime}=U_{n}$, а величина $x=U_{n} / \bar{U}$ уменьшится в $W$ раз. С другой стороны, масштабный фактор цены $p_{0}=\bar{U} / r_{0}$ увеличится во столько же раз. Предположим, что цена $p$ не изменится сразу же вслед за эмиссией, то есть временной фактор $\alpha N$ невелик, и вначале $p=p^{\prime}$. Тогда величина $y=p / p_{0}$ уменьшится во столько же раз, что и $x$. Это означает, что, осуществляя эмиссию по данному сценарию, общество будет двигаться от состояния 1 к началу координат по отрезку $A O^{2}$ (см. рис. 6). При некоторой величине эмиссии $M^{\prime}$ общество пересечет сепаратрису и войдет в область, откуда оно, будучи предоставленным самому себе, через некоторое время перейдет в устойчивое стационарное состояние 3.

Рассмотрим теперь эмиссию, адресованную работникам. В этом случае величина их накоплений в денежном выражении увеличится на размер эмиссии, что повлечет за собой увеличение $x\{\Delta x=(W-1) / W(1 / n-x)\}$ и, соответственно, $r_{n}$ и платежеспособного спроса. В то же время величина $y$ уменьшится в $W$ раз: $\{\Delta y=-(W-1) / W y\}$, как и в предыдущем случае. Это означает движение общества из состояния 1 вправо и вниз по отрезку $A B$, составляющему тупой угол с осью $O X\left\{\Delta y / \Delta x=-\left(1 / n-x_{A}\right)^{-1}, x_{A}\right.$ - фиксировано $\}$ и пересекающему ось в точке $x_{B}=1 / n$. При некоторой величине эмиссии кривая может пересечь сепаратрису и попасть в область, откуда общество уже само перейдет в состояние 3. Однако, поскольку сепаратриса также направлена под тупым углом к оси $O X$, может оказаться, что пересечения не произойдет или для этого потребуется слишком большая величина $M^{\prime}$. Какая именно, во многом зависит от наклона сепаратрисы, то есть от величины $\alpha N$. Во всяком случае, она больше, чем в первом варианте эмиссии.

Таким образом, наше качественное рассмотрение вариантов эмиссии привело к тривиальному выводу: эмиссию намного выгоднее проводить с целью расширения производства, а не простого увеличения спроса. Разумеется, это рассмотрение носит иллюстративный характер и не претендует на количественное описание, поскольку в реальности в обществе задействовано одновременно много каналов перетекания денег из одной сферы в другую. В то же время пример с эмиссией показывает, что грубо, на качественном уровне наша модель схватывает основные свойства, присущие обществу, находящемуся в состоянии далеком от устойчивого.

\footnotetext{
${ }^{2}$ При изменении $M$ происходит изменение фазового портрета общества, однако в силу масштабной инвариантности можно, оставив фазовую картину прежней, свести изменение $M$ к изменению положения общества на плоскости $X-Y$.
} 


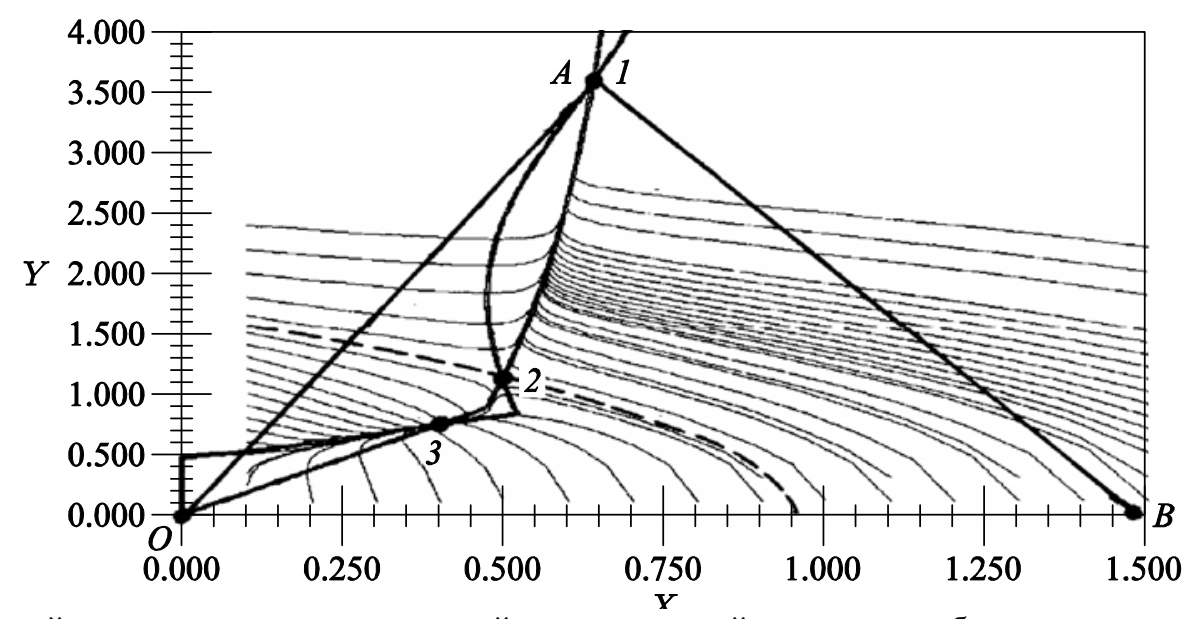

Рис. 6. Фазовый портрет системы уравнений, описывающей замкнутое общество в однопродуктовом приближении. По оси абсцисс - накопления работников, по оси ординат — цена товара (в относительных единицах). Жирные линии - изоклины $d x / d t=0$ и $d y / d t=0$. Точки пересечения изоклин определяют стационарные состояния (1 и 3 - устойчивые, 2 - неустойчивое). Тонкие линии - траектории эволюции общества. Каждой точке траектории соответствует определенное значение времени. Эволюция общества начинается с краев рисунка и заканчивается в точках стационарного состояния. Штриховая линия - сепаратриса. Результат внешнего воздействия в виде эмиссии денег: отрезок $A O$ показывает результат эмиссии, адресованной владельцам. Отрезок $A B$ показывает результат эмиссии, адресованной работникам (см. пояснения в тексте) [Чернавский, Щербаков, Старков, 2015]

Выше показано, что адресная эмиссия в нужный момент и в нужном объеме также может перевести общество из состояния 1 (стагнация) в состояние 3 . В рамках модели более целесообразно адресовать эмиссию владельцам, работающим в реальном секторе (другие сектора в модели пока не рассматривались).

В благополучном состоянии 3 поляризация тоже невелика, хотя и больше, чем в состоянии 1. При учете «размывания» страт общество становится практически унимодальным, поскольку степень удовлетворения всех групп практически одинакова. В этом случае эмиссия денег также смещает изображающую точку вниз. При этом цены в номинальном исчислении в момент эмиссии сохраняются, но затем возрастают, и система возвращается в исходное состояние (но при более высоких номинальных ценах). В результате эффект сводится к реноминации денег.

Эти эффекты эмиссии можно сопоставить с кейнсианской и монетаристской моделями. Строго говоря, детальные сопоставления невозможны, поскольку в нашей модели не учтены еще рынки денег и труда, которые в упомянутых концепциях играют важную роль. Тем не менее качественные эффекты сходны. Так, переход общества от стагнации к развитию за счет достаточно большой эмиссии - типичный для кейнсианских моделей эффект. Эффект роста номинальных цен (номинальной инфляции) в состоянии 3 или при недостаточной эмиссии в состоянии 1 типичен для моделей монетаристского типа.

Подчеркнем, что эти выводы относятся к закрытому обществу. В экономически открытом обществе ситуация принципиально меняется. Результат зависит от экономического состояния партнера. Если партнер более развит, то появляется возможность продавать свой товар (сырье) именно ему и получать конечный продукт оттуда. Заинтересованность в благополучии своих рабочих при этом уже отсутствует.

В целом модель открытого общества заслуживает специального рассмотрения.

\section{Заключение}

В последние годы наша группа, возглавляемая Дмитрием Сергеевичем Чернавским, работала над совершенно новой, но крайне актуальной задачей - моделированием цифровой эко- 
номики. Дело в том, что спор, длившийся последние 50 лет XX века между последователями Кейнса и Фридмана, в настоящее время не актуален. На смену обычным экономическим взаимоотношениям приходит цифровизация. Это не просто перенос экономики из бумажного пространства в виртуальное, это совершенно новый этап экономических взаимоотношений, со своими правилами и законами. Именно изучением этих новых экономических законов и формулированием новых правил взаимодействия субъектов экономики занимаемся мы последние полтора года. Это крайне интересная тема, и на этом пути нас ожидает много открытий и свершений. И в качестве заключительного пожелания хочется привести слова Д. С. Чернавского, сказанные им буквально за день до смерти:

\section{«Не разменивайтесь на мелочи, занимайтесь фундаментальными вопросами!»}

\section{Д. С. Чернавский}

\section{Список литературы (References)}

Аллен Р. Математическая экономия. - М.: Издательство иностранной литературы, 1963. Allen R. Matematicheskaya ehkonomiya [Mathematical Economics]. - Moscow: Publishing house Foreign literature, 1963.

Блауг М. Экономическая мысль в ретроспективе. - М.: Дело, 1994.

Blaug M. Ehkonomicheskaya mysl' v retrospektive [Economic thought in retrospective]. — Moscow: Delo, 1994.

Кейнс Дж. М. Избранные произведения. - М.: Экономика, 1993.

Keynes J. M. Izbrannye proizvedeniya [Selected works]. — Moscow: Ekonomika, 1993.

Ларуш Л. Физическая экономика. - М.: Научная книга, 1997. LaRouche L. Fizicheskaya ehkonomika [Physical Economics]. — Moscow: Scientific book, 1997.

Лебедев В. В. Математическое моделирование социально-экономических процессов. - М.: Изограф, 1997.

Lebedev $V . V$. Matematicheskoe modelirovanie social'no-ehkonomicheskix processov [Mathematical modeling of socio-economic processes]. — Moscow: Izograf, 1997.

Маевский В. И. Введение в эволюционную макроэкономику. - М.: Япония сегодня, 1997. Maevsky V.I. Vvedenie $\mathrm{v}$ ehvolyucionnuyu makroehkonomiku [Introduction to evolutionary macroeconomics]. Moscow: Japan today, 1997.

Полтерович В. М. Институциональные ловушки и экономические реформы / Российская экономическая школа, Working paper \#98/004, M., 1998.

Polterovich V. M. Institucional'nye lovushki i ehkonomicheskie reformy [Institutional traps and economic reforms] / New Economic School, Working paper \#98/004, M., 1998.

Робинсон Дж. Экономическая теория несовершенной конкуренции. - М.: Прогресс, 1986. Robinson J. Ehkonomicheskaya teoriya nesovershennoj konkurencii [Economic theory of imperfect competition]. Moscow: Progress, 1986.

Хикс Дж. Р. Стоимость и капитал. - М.: Прогресс, 1988. Hicks J. R. Stoimost' i kapital [Value and capital]. - Moscow: Progress, 1988.

Чернавский Д. С. У верблюда два горба, потому что жизнь борьба // Солидарность. № 9-10. - M., 1991.

Chernavskii D. S. U verblyuda dva gorba, potomu chto zhizn' bor'ba [The camel two humps, because life is a struggle] // Solidarnost' [Solidarity]. — No. 9-10. — Moscow, 1991.

Чернавский Д. С., Пирогов Г. Г., Чернавская О. Д., Щербаков А. В., Суслаков Б. А. Динамика экономической структуры общества // Прикладная нелинейная динамика. — 1996. — Т. 4, № 3. - C. 67-75.

Chernavskii D. S., Pirogov G. G., Chernavskaya O.D., Scherbakov A. V., Susekov B. A. Dinamika ehkonomicheskoj struktury obshhestva [The dynamics of the economic society structure] // Prikladnaya nelinejnaya dinamika [Applied nonlinear dynamics]. — 1996. - Vol. 4, no. 3. - P. 67-75.

Чернавский Д. С., Суслаков Б. А., Чернавская О. Д., Пирогов Г. Г., Старков Н. И. О социальноэкономической структуре общества // Законодательство и экономика. - 1995. Вып. 7/8. - С. 8-14. 
Chernavskii D. S., Susekov B. A., Chernavskaya O. D., Pirogov G. G., Starkov N. I. O social'no-ehkonomicheskoj strukture obshhestva [On the socio-economic structure of society] // Zakonodatel'stvo i ehkonomika [Law and Economics]. - 1995. - Vol. 7/8. - P. 8-14.

Чернавский Д. С., Щербаков А. В. Доллар. Окно возможностей и пирамида. — http://mendeleevcenter.ru/articles/article-0007.html — Опубликовано: 14.04.2015 (дата обращения: 12.04.2017).

Chernavskii D. S., Shcherbakov A. V. Dollar. Okno vozmozhnostej i piramida [Dollar. The window of opportunity and a pyramid]. — http://mendeleev-center.ru/articles/article-0007.html (accessed 12.04.2017).

Чернавский Д. С., Щербаков А. В. Экономика России: стабилизация или застой? // Полития. № 3(5). - М., 1997.

Chernavskii D. S., Shcherbakov A. V. Ehkonomika Rossii: stabilizaciya ili zastoj? [The Russian Economy: stabilization or stagnation?] // Politeia. — No. 3(5). — Moscow, 1997.

Чернавский Д. С., Щербаков А. В., Старков Н. И. Динамическая модель закрытого общества (институциональные ловушки и кризисы). - http://mendeleev-center.ru/articles/article0018.html - Опубликовано: 29.05.2015 (дата обращения: 12.04.2017).

Chernavskii D. S., Scherbakov A. V., Starkov N. I. Dinamicheskaya model' zakrytogo obshhestva (institucional'nye lovushki i krizisy) [Dynamic model of a closed society (institutional traps and crises)]. - http://mendeleevcenter.ru/articles/article-0018.html (accessed 12.04.2017).

Чернавский Д. С., Щербаков А. В., Старков Н. И., Суслаков Б. А. Ценообразование при максимальной прибыли // Экономические и математические методы. - 1998. - Т. 34, вып. 2. - C. 44-54.

Chernavskii D. S., Scherbakov A. V., Starkov N. I., Susekov B. A. Cenoobrazovanie pri maksimal'noj pribyli [Pricing for maximum profit] // Ehkonomicheskie i matematicheskie metody [Economical and mathematical methods]. 1998. - Vol. 34, issue 2. - P. 44-54.

Fridman M. The Quantity Theory of Money: Restatement // M. Fridman (Ed.), Studies in Quantity Theory of Money, Chicago, The University of Chicago Press, 1956; "Quantity Theory", In International Encyclopedia of the social Services, 1968. - Vol. 10. 